\title{
Attitude, Knowledge and Behavior about Sexuality among Adolescents
}

\author{
Srimonti Guha
}

\begin{abstract}
The children of today are not the children of yesterday. Growth in terms of maturity and knowledge can be seen on a large scale for the adolescent population of today. Notions and ideas about sexuality were a prohibited topic till long time back but now adolescents are much aware and filled with various kinds of knowledge on the same. Researchers have shown that parents play the most significant role in imparting sex education to their adolescent children. They have been found to be the primary sex educators where basic and the initial knowledge about sexual attitudes and the like are conveyed on to the children. This study is basically on the attitudes, knowledge and behavior about sexuality among adolescents. It has been done by gathering data on the previous research studies conducted in this area. A combination of thirteen distinct articles and research studies have been reviewed and critically analyzed through content analysis. The age range of the children in the articles reviewed varied from 09 to 15 years of adolescents and parents of children who were 03-06 years of age were also included the articles. The articles portrayed that fathers need to be more involved in discussing about various topics related to sexuality, mothers should be more willing to talk more with their sons about topics related to sexuality and there should be reduction in the gender bias.
\end{abstract}

Keywords: Adolescents, Parents, Communication, Sexuality.

Table of Contents

Approval of dissertation

Declaration

Certificate

Acknowledgements

Abstract

List of Tables

List of figures

Chapter I: Introduction

Chapter 2: Review of Literature

Chapter 3: Methodology

Chapter 4: Results and Discussion

Chapter 5: Conclusions

References

List of Tables

\begin{tabular}{|l|l|l|}
\hline Serial Number & Title & Page Number \\
\hline 1 & $\begin{array}{l}\text { Table showing the retrieved International } \\
\text { and National Articles with their year }\end{array}$ & $17-20$ \\
\hline
\end{tabular}

\section{Introduction}

The process of acquiring information and forming attitudes and beliefs about sex, sexual identity, relationships and intimacy is known as sexuality education or sex education or sex and relationships education. Sexual behaviors, such as unprotected intercourse, and sex with multiple partners, place young people at risk for pregnancy and sexually transmitted diseases (STDs), including human immunodeficiency virus (HIV) infection. Hence sex education is about developing young people's skills so that they make informed choices about their behavior, and feel confident and competent about acting on these choices. It has been accepted widely that there is an immense need for students to get sex education as it will in turn help them to mature and will also guide them to follow the right track and they are helped to protect themselves against abuse, exploitation, unintended pregnancies, sexually transmitted diseases and HIV and AIDS. It is also argued that providing sex education helps to meet young people's rights to information about matters that affect them, their right to have their needs met and to help them enjoy their sexuality and the relationships that they form. Sex education helps to reduce the risks of potentially negative outcomes from sexual behaviors and also aims to contribute to young people's 
positive experience of their sexuality by enhancing the quality of their relationships and their ability to make informed decisions over their lifetime. Few other scholars have said that sex education is a broad term used to describe education about human sexual anatomy, sexual reproduction, sexual intercourse, and other aspects of human sexual behavior. Some form of sex education is a part of the curriculum in many institutions but it still remains a very controversial issue in many countries particularly with regard to the age at which children should start receiving such education, the amount of detail which is revealed, and topics dealing with human sexuality and behavior (e.g. Safe sex practices and masturbation, and sexual ethics). In USA sex education raises much contentious debate among the citizens. The chief among controversial issues which has been brought into the focal area is whether covering child sexuality is valuable or detrimental; the use of birth control such as condoms and oral contraceptives; and the impact of such use on pregnancy outside marriage, teenage pregnancy, and the transmission of STDs. Countries which are having very high rate of conservative attitudes towards sex like U.S.A. and U.K. to mention a few have a higher incidence of STDs and teenage pregnancy. The skills that can be learnt through sex education are related to more general life-skills. The act of being able to communicate, listen, negotiate with others, ask for and identify sources of help and advice, are useful lifeskills which can be applied to sexual relationships. If there is an effective sex education it helps in developing young people's skills in negotiation, decision-making, assertion and listening. There are varied other important skills which include being able to recognize pressures from other people and to resist them, dealing with and challenging prejudice and being able to seek help from adults - including parents, careers and professionals through the family, community and health and welfare services. In the sphere of sex and sexuality young minds can be exposed to a wide range of attitudes and beliefs towards sex and sexuality which may sometimes appear to be contradictory and confusing in the way it is portrayed. Some health messages focuses on the risks and dangers associated with sexual activity and some media coverage promotes the idea that being sexually active makes a person more attractive and mature which can in turn lead the individual develop false attitudes and beliefs. As sex and sexuality are very sensitive subjects' young people and sex educators can have strong views on what attitudespeople should hold, and what moral framework should govern people's behavior which can also seem to be odd. In the adolescent stage when people are slowly getting involved in knowing the world at a larger perspective and framework they often welcome opportunities to talk about issues where people have strong views and beliefs, like abortion, sex before marriage, lesbian and gay issues and contraception and birth control and it is important to remember that talking in a balanced way about differences in opinion does not promote one set of views over another, or mean that one individual agrees with a particular view. It is a part of exploring and understanding cultural, religious and moral views and finding out the fact on what we can agree or disagree. Those individuals who are providing sex education have attitudes and beliefs of their own about sex and sexuality and it is important not to let these influence negatively the sex education that they provide to the people at large as based on their orientation and beliefs one forms their belief and perspective. A very interesting fact is that there has been a history of sex education. But researches haven't done so vast in relation with the history in the domain of sex education. During the 20th century the research that has been done is mainly about school sex education. School sex education is important, though most of us learn little of what we know about sex from our schooling or through the school sex education and the majority of knowledge that we gather is from friends, from family and, increasingly, from the media. From the late 19th century onwards in England, a number of sex education publications were produced, which mainly focused in helping parents to enlighten their children. Before Second World War in school little formal school sex education started taking place mainly in the context of 'hygiene'. Senior girls were provided with instruction on such topics as 'selfreverence, self-control and true modesty', and to boys, on leaving schools, being given talks on the 'temptation of factory and workshop life', with special reference to sex as researchers have collected data. A drastic change has taken place during the phase of Second World War for most of the population of Europe and also countries beyond. Due to the extensive mass movement of people there has been a significant increase in the incidence of sexually transmitted infections and the outbreak of war resulted in the increase of sex education in schools and one of the main aims was towards the prevention of syphilis and gonorrhea. During the 1950s and 1960s school sex education in the UK mainly focused through the description though not the observation of reproductive habits of plants and non-human animals and it was apparently viewed that boys when they were educated in the public school may still have sometimes received warnings about the dangers believed to follow from masturbation and the teaching of human reproductive system became more widely subject to be focused on to. Due to the great social changes of 1960s and 1970s there was a significant change in the school sex education. The textbooks of biology started giving detailed accounts of the human reproductive system and on the other hand the method of contraception was taught widely. The emphasis was mostly on the provision of accurate information and aims of sex education programmes included significant factors like decrease in ignorance, guilt, embarrassment and anxiety. Other significant issues to do with relationships were probably more often discussed in programmes of personal and social education, rather than in biology lessons. Gradually by 1980s there was a heightened increase in the aims of sex education with the growing acceptance of feminist-thinking 
which in turn led to an increase in the number of programmes that encouraged pupils to examine the roles played by women and men in society at large. The aim was for the students to realize the existence and the extent to which gender inequality was prevalent in the society and it was the feminist critiques who pointed out on how sex education programmes at many times reinforced gender inequalities in the broader spectrum. While on the other hand at the same time sex education programmes increasingly began to have aims throwing light on the acquisition of skills for decision-making, communicating, personal relationships, parenting and coping strategies. But it was also seen that pupils continued toreceive little school sex education, and the knowledge that they gained was a rather brief and narrow education, in biology lessons, about puberty and human reproduction and it was clear that few pupils were given much opportunity to discuss anything about sexual feelings and relationships. But not to ignore the facts as the importance of skills became acknowledged, so sex education programmes increasingly talked about enabling young people to think for themselves and make their own informed decisions about issues that concerned their sexuality and which gradually increased the enhancement of school sex education. The post Second World War brought into notice about a new sexually transmitted agent - HIV which was rapidly spreading in many countries of the world. There was a near panic set in, in some quarters, as it became appreciated that many, perhaps most, people infected with HIV would go on to develop AIDS and subsequently die. HIV and AIDS became a health issue in the UK at just the time that sex education became a political football in the society at large. A number of circumstances, including the controversy over the 1985 case of Gillick, which focused on whether parents always have the right to know if their children are being issued with contraceptives when under the age of 16 , and the growing strength of the lesbian and gay movement, which led to a polarization of views on sex education, among politicians at local and national level and it was believed that a value-less sex education would not be encouraged. The aims of the recent school education mainly focus to ensure that young people do not engage in heavy petting or sexual intercourse before marriage. At the other end of the spectrum, some sex education programmes challenge sexist and homophobic attitudes, try to help young people make their own decisions about their sexual behavior and discuss issues of sexual pleasure. Modernization and progress has eventually opened a Pandora's Box of opportunities and learning for the youth and this in turn makes sex education important for kids. As they are young they are unpredictable and they arealways in the mood to take risks which in turn becomes vulnerable for them. It is very much virtually evident that there are a large number of unwanted teen pregnancies, teen miscarriages, abortions and the spread of STDs. Sometimes it happens that as many parents did not get proper sex education from their own parents they feel inhibited to discuss about the topic with their children. The question always revolves that how they are going to start off with a topic and how they are going to make them understand and what if they are not able to answer their questions and like this several other questions tend to flash across their minds. There is the constant fear when the children is in adolescent that talking about sex will encourage a child to experiment with sex too early or before they're mature enough to deal with it and hence it shouldn't be a shocking news to hear that majority of the parent population leave it to the schools to discuss. But still parents fear that though they are going to learn about the varied information related to sex education which in turn can take away their innocence. Another factor which should be taken into consideration is that when the schools are trying their level best to encourage parents to engage themselves through showing video clippings and pictures and having discussion many are too embarrassed or don't think it's important enough to turn up for the discussion which can be a negative point. Sometimes when schools teach sex education there can be professional groups who can critique against it and say that it is the parents' responsibility to teach their children about sexuality. Studies have shown that when parents were free and open with their children about topics related to sex and sexuality it has enhanced children's understanding over the subject and they are most likely to follow the advice and the guidance provided by their parents than the media or peer group or outside external sources. Researchers have proved through their studies that the right age to start talking about varied issues of sex and sexuality is when the child is in the stage of adolescence. Not only the practical aspects of pregnancy and intercourse should be taught but also the adolescence has to be taught about birth control and parents should not be afraid in talking with their children about sex and sexuality as Indulging in talks related to sex and drugs help children to judge wisely when they are faced with similar situations. And if one is still very conscious in talking with their children then a parent should take help from a medical practitioner. And as children look up to their parents for the right knowledge. Hence it will help them tremendously if the parents get their facts right before talking to their children. It should always be kept in mind that children's life decisions could depend on the knowledge parents will be sharing with them and keeping this factor in mind will help parents to overcome any fear or embarrassment one may feel about sex education. It is when parents talk to and affirm the value of their children; young people are more likely to develop positive, healthy attitudes about themselves. According to Barbara Huberman, RN, MEd, Director of Education and Outreach for Advocates for Youth, parents who act on the belief that young people have the right to accurate sexuality information are parents whose teens will delay the initiation of intimacy and use contraceptives when they choose to become sexually active. It has been proved by various researchers through their researches that good parent-child 
communication around sexuality has many positive effects for teens - including helping them protect their own sexual health and good parent child communication leads to better contraception use and lower sexual risk behaviors. Research has found that more teens would prefer to get information about contraceptives from their parents than from a health center, class, hospital, media or friends. It has been proved by researches that young people who feel a lack of parental warmth, love or care or in simpler terms there is less attachment and emotional bonding with the parent were more likely to report emotional distress, school problems, drug use and sexual risk behaviors Young people also report less depression and anxiety and more self-reliance and selfesteem than other peers who discuss sex with their parents. When there is a confident parent child relationship and communication related to sex and sexuality leading to improved contraceptive and condom use, improved communication about sex and fewer sexual risk behaviors among adolescents. In a recent study, teens that have reported in having a healthy discussion with parents in the last year about sex, birth control and the dangers of STDs were two times more likely to use condoms the last time they had sex than teens who did not talk to their parents as often regarding the varied facets about sexuality. Few researches have also shown that if mothers discussed about condom use with their adolescent kid before they indulged themselves into sexual intercourse had higher chances of taking precautions than those adolescence whose mothers never engaged in communication related to sex and sexuality.

As very rightly said adolescence is a period of storm and stress and it is the period of change from the immaturity of childhood and to step into maturity of adulthood. Early adolescence is considered to be the most critical stage of development, a period of accelerated growth and change. The behavior patterns which are adopted in these years can have lifelong consequences, both positive and negative for an individual. Early adolescence is a time of opportunity and risk and a positive school environment is critical to ensuring this age group's learning, social, and physical needs are met Along with that the support and guidance from parents is one of the most important facet which can mould the individual in the best positive way or the least positive way. In recent times rather in the present society at large it is immensely important to impart sex education among teenagers. During adolescence, it is not only the hormones which work overtime, but there are physical changes too that are taking place in the body structure; particularly in the sex organs, making the teenager curious to explore these changes and added to all these factors there is an immense urge in taking risks in life and to indulge what is forbidden combined with the absence of adequate wisdom to control these impulses. The 'sexual arena' is in constant focus among the teens; in the absence of proper guidance, this can result in more harm than good. Researchers have proved that sex education will help in preventing teenage pregnancies, besides teenage pregnancy being a health hazard adolescents are not in a stage to handle pregnancy, child birth or to become a parent. The impact of sex education, teenagers will be better equipped to understand the repercussions of teenage pregnancy on their health as well as that of the fetus and they will recognize the importance of pre- delivery care and the consequences of hiding a pregnancy. Sex education will help teenagers appreciate the negative impact of teenage pregnancy on their education, and consequently on their future, so that they would take necessary steps to avoid it. It is always better to be safe than to be sorry. In the year 2002 the Central Board of Secondary Education (CBSE) had asked the schools to incorporate the subject of sex education in schools across the country, but in reality there are more schools that are hesitant about educating their students about sex than the schools, which had gone ahead with the inclusion of the topic. Sex education as a subject is yet to be accepted as a normal part of the school curriculum, and the problem is not only in India alone. The main debate that has been revolving round the subject is what benefits will the children receive from getting sex education and it has shown by researchers that it has helped adolescents to take better decisions and to follow the right path of life. There are certain factors that help in communication are careful listening, clear speech with direct eye to eye contact, stating the feelings which are going across the mind and one of the most significant points of respecting each other's point. There should be offering of solutions to the various smile and positive non-gestures to comfort like a smile. Sex education to the teens can help to avoids or decrease the incidence of teenage pregnancies with an increase self-restraint on indulgence in sex. There is an increase in their awareness and usage of contraceptive methods, including the use of condoms and to prevent or decrease the rate of sexually transmitted diseases such as gonorrhea, non-gonoccocal urethritis, pelvic inflammatory disease and syphilis. It can help to prevent, control or decrease the HIV/AIDS. There are various aspects which need to be followed when a parent is having a talk with their children especially on topics like sex and sexuality. The first aspect understands the fact that adolescents have a culture of their own and the parents cannot be a part of that culture. The culture gap can become a real wall between the parent and the adolescent. It is important for the parents to understand their child's need for a special culture. The parents also have to choose the areas of disagreement. The second factor which should be taken consideration is timing where scheduling a certain time each week to talk to the adolescent may be needed. The parents should act as if they are looking forward to them and enjoy them and meetings like that should be completely informal. Adolescents should feel relaxed and open up to their parents. The third and fourth aspect is listening and feeling, a parent should listen to what their adolescent kid has to say and also feel empathetic and through touching and giving 
the love and assurance makes the communication more effective and helpful for both the adolescent and their parents.

The major purpose of the research is to study the phenomenology of Attitude, Knowledge and Behavior about Sexuality among Adolescents. The exploration of the research was mainly done through the vast pool of available literature in the domain of sexuality at large and concerning mainly with the adolescence as that is the most significant stage in the developmental period when the person moulds. The significance of the study is that it aims to provide strong links between the knowledge and behavior revolving around an adolescents life in terms of sexuality and the attitude that one possess and the effect of the parents in educating their adolescent children about sexuality and the impact that it brings in the adolescence than when the varied information is passed across through media or through peers. The major implications which the present research focuses on mainly the development of programs related to sexuality and open forums for parents to discuss about the various topics in the sphere of sexuality and to educate the parents, teachers at large in the domain of sexuality so that there is an eradication of various misconceptions and misinterpretations about the varied aspects in relation to sexuality in turn changing the outlook of adolescents towards sexuality. The specific objectives which the research focuses on are the differences between boys and girls in discussing about matters related to sexuality, the difficulties faced by parents in not discussing the similar amount of information irrespective of gender, the varied cultural aspects related in terms about discussing topics in regards to sexuality. The reason for the varied misinterpretations of the different meanings and misinterpretations and various sub topics under the major umbrella term "Sexuality". One of the major objectives is to view that whether parents play a major role in being sex educators as compared to media and peers and the impact it has to the adolescence mind at large knowing the fact that adolescence is the most important phase in the life span of an individual and the age of transformation. The study will help parents to learn more about sexuality which will in turn lead the adolescents to have a much broader outlook about the topic at large, a topic which has been avoided or misinterpreted in the broader spectrum being a culturally sensitive topic and sometimes due to the extensive lack of knowledge from the parents' side which has brought in a barrier in the communication about sensitive topics like sexuality with adolescence.

Aim- The aim of the study is to determine the Attitude, Knowledge, Behavior about Sexuality among Adolescents.

Objectives: -

- To study the knowledge, attitude and behavior about sexuality among adolescents

- To study the role of parents in sex education

- To study the gender differences in sex education

- To study the methods of improving communication in sex education

- To study the taboos related to sex education

Hypotheses: -

- Sex education from parents helps the adolescents in attaining concrete sexual knowledge

- Gender bias prohibits attainment of sex education by girls

- Mothers discuss about sex more frequently with girls than boys

\section{Review of Literature}

According to a study by ShashikumarRamadugu, VSSR Ryali, K. Srivastava, P.S. Bhatt and J.Prakash on Understanding sexuality among Indian Urban school adolescents in the year 2012 portrayed that adolescent school students or adolescents are involved in various sexual activity, but they lack adequate knowledge in the sphere of sexuality. Students, teachers and parents should need to understand the various aspects of sexuality which will in turn help the adolescents' healthy sexual development.

Sarah C. Wyckoff, Kim S. Miller, Rex Forehand, J.J. Bau, Amy Fasula, Nicholas Long and Lisa Armistead conducted a research study on the Patterns of Sexuality Communication Between Preadolescents and their Mothers and Fathers in the year 2007 portrayed that mothers and fathers were equally likely to communicate with sons whereas mothers were more likely to communicate with daughters than were fathers and the study also signifies that preadolescence may be the optimal time for parents to provide sexual risk prevention messages to their children before sexual behaviors are initiated.

A study conducted on Gender Differences in the ABC'S of the Birds and Bees: What Mothers teach Young children About Sexuality and Reproduction in the year 2010 reported that mothers talk more to daughters than sons about romantic relationships, reproductive bodies, and morality, but not about sexual abuse or intercourse/pleasure and there exists mixed results regarding mothers' comfort in talking with daughters or sons about sexuality. 
According to a study by Shelly Saha on Adolescents and their need for sex- education showed that early sexual initiation can lead to tragic social, economic and health consequences and the fact that in recent years the increased travel, tourism, migration, the global availability to mass media, changes in family structures, loosening of traditional constraints, early start to puberty and also due to late marriages leads to the changing patterns of sexual behavior among young people. It has also been portrayed that in the urban areas young people get indulged in premarital sex as they marry later and are more at risk of unwanted pregnancy, and STDs. Due to the gender inequity, adolescent girls are more vulnerable to high-risk sexual relations. Through the study they also showed that there was an increase in Sexually Transmitted Disease prevalence among young people with a rapid increase in HIV infections among 15-24 years, there was also inadequate knowledge about reproductive health and needs and early marriage and early pregnancy with high fertility rates found among adolescents.

Peter Scales used paradigm concept to critically review sexuality education methods and impact over last 35 years portrays that few paradigms have been employed that are successful in reaching their goals, and that the most effective paradigms are often refuted or resisted due to the various moral-political implications and also focuses on the fact that health promotion paradigm may be one of the most effective approach to have a positive future impact on the personal behavior.

Kimberley Burns conducted a case study of a school in eastern Uganda in relation to sexuality education and the main fact that came into the limelight is that gender roles hinder sexuality education and that gender roles and expectations restrict the amount of information that

girls receive about sexuality in school increasing their chances of contracting HIV, falling pregnant and losing educational opportunities.

\section{Methodology}

Research Design: - The research design was based on reviewing articles related to Attitude, Knowledge and Behavior about Sexuality among Adolescents.

Type of Study: - The type of study comprised of the review of various articles related to the topic.

Sample Size: - The sample size was sixteen articles chosen in relation to the topic.

Sample Characteristics: - The articles which were reviewed was based on studies conducted among adolescents of both the genders (male, female) between 09 to 15 years of age and parents of kids of ages 03 to 06.

Statistical Analysis: - The statistical analysis that was mainly used for reviewing the articles was Content Analysis.

\section{Procedure: -}

- After the topic was finalized, 16 different articles related to the topic of study were collected and reviewed.

- The results and findings of the articles were critically analyzed in order to support or refute the hypotheses of the current study.

- The findings obtained from the analysis of the selective literature were then presented and discussed in a detailed manner.

\section{Results and Discussion}

After an extensive reviewing and critically analyzing the vast pool of literature there has been both quantitative and qualitative results which were brought into notice of the author which will be discussed in more extensive details.

Table showing the retrieved International and National Articles with their year

\begin{tabular}{|c|c|c|}
\hline Year & International Articles & National Articles \\
\hline 1990-1995 & $\begin{array}{l}\text { - Sexuality Education of Young } \\
\text { Children: Parental Concerns- } \\
\text { Margie J. Geasler, Linda L. } \\
\text { Dannison, Connie J. Edlund } \\
\text { Sexuality Education: What } \\
\text { Daughters in Their 30s Wish } \\
\text { their Mothers Had Told Them- } \\
\text { Linda J. Brock, Glen H. Jennings } \\
\text { The Changing Context of } \\
\text { Sexuality Education: Paradigms } \\
\text { and Challenges for Alternative } \\
\text { Futures- Peter Scales }\end{array}$ & Not Retrieved \\
\hline $1995-2000$ & $\begin{array}{l}\text { - Sexuality Education in a Girls' } \\
\text { school in Eastern Uganda- }\end{array}$ & $\begin{array}{ll}\text { - } & \text { National Family Health Survey } \\
\text { - } & \text { Menstrual Pattern and growth of }\end{array}$ \\
\hline
\end{tabular}




\begin{tabular}{|c|c|c|}
\hline & $\begin{array}{l}\text { Kimberley Burns } \\
\text { - Rural Parents' Communication } \\
\text { With their Teen-agers about } \\
\text { sexual issues- Timothy R. } \\
\text { Jordan, James H. Price, Shawn } \\
\text { Fitzgerald }\end{array}$ & $\begin{array}{l}\text { School girls in Mumbai- } \mathrm{R} \mathrm{A} \\
\text { Vaidya, MA Bhatt }\end{array}$ \\
\hline $2000-2005$ & Not Retrieved & $\begin{array}{l}\text { Knowledge and behavior and } \\
\text { attitudes about adolescent } \\
\text { sexuality among adolescents in } \\
\text { Pune- AG Sathe, S Sathe }\end{array}$ \\
\hline $2005-2010$ & $\begin{array}{l}\text { - Gender Differences in the ABC's } \\
\text { of the Birds and the Bees: What } \\
\text { Mothers Teach Young Children } \\
\text { About Sexuality and } \\
\text { Reproduction- Karin A. Martin, } \\
\text { Katherine Luke. } \\
\text { Patterns of Sexuality } \\
\text { Communication Between } \\
\text { Preadolescents and Their } \\
\text { Mothers and Fathers- Sarah C. } \\
\text { Wyckoff, Kim S. Miller, Rex } \\
\text { Forehand, J.J. Bau, Amy Fasula, } \\
\text { Nicholas Long, Lisa Armistead. }\end{array}$ & $\begin{array}{l}\text { Prevalence and Patterns of } \\
\text { Alcohol Consumption and } \\
\text { Health-Risk Behaviors among } \\
\text { high school students in Thailand- } \\
\text { S. Assanangkornchai, A. } \\
\text { Mukthong. }\end{array}$ \\
\hline present & 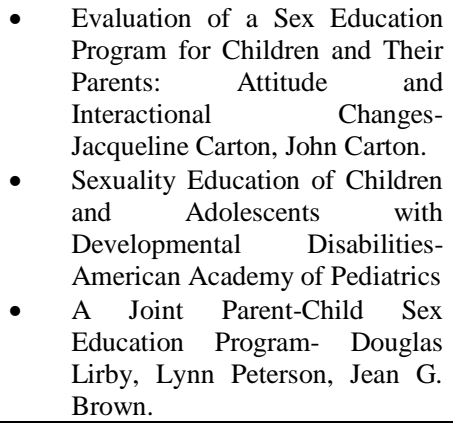 & $\begin{array}{l}\text { - Understanding Sexuality among } \\
\text { Indian Urban School } \\
\text { adolescents- } \\
\text { ShashikumarRamadugu, VSSR } \\
\text { Ryali, K. Srivastava, P.S. Bhat, } \\
\text { and J. Prakash. } \\
\text { Adolescents and their need for } \\
\text { sex education- Shelly Saha }\end{array}$ \\
\hline
\end{tabular}

Adolescence has been termed as one of the most significant stage in the lifespan when the human minds are always on the edge of taking varied risks. According to a survey of March 2000, 22.8\% of the population in India comprised of adolescence and it was also found that they were highly affected by the bodily changes during this stage of life. Sathe and Sathe conducted a research study in Pune among the adolescents found that although adolescence have little or sometimes negligible amount of knowledge in regard to human sexuality but still $22 \%$ of the boys and $5 \%$ of girls have already experienced premarital sex. Adolescents often misunderstood varied phenomenon like menstruation, masturbation, pregnancy etc. As it has been seen that parents are always not able to provide enough or correct knowledge to their adolescent children the adolescents show more concern in this regard and due to their lack of information many children maybe the victims of sexual abuse. In one of the researches ShashikumarRamadugu et al. the knowledge that the adolescence possessed about HIV was assessed on the correctness of the five given questions as given on the questionnaire which had to be answered. Each correct answer fetched a score of 1 and based on the scoring three were three distinctions, those who obtained a score of 4-5 marks were grouped as having good awareness (G) about HIV, those adolescent students who had a score of 3 were grader as average (A) awareness and those who obtained a score of 2 or less than that were graded as having poor awareness (P) about HIV indicating that the adolescents was not aware of the different facts governing to HIV. In the similar way the adolescence children were graded on the domain of masturbation, menstruation and intercourse. Under the domain of masturbation there were mainly three questions and was graded as good awareness on masturbation if the adolescence has a score of 3 , average if the individual has a score of 2 and poor awareness if the score is 1 . On the sphere of menstruation there were four questions and the grading was done if the adolescence has answered 3-4 questions correctly then was graded as having good awareness, if the individual gets a score of 2 then average awareness and if individuals score 1 or less then the adolescence have poor awareness. And finally on the domain of intercourse there were 4 questions and the grading was done similar to the way as it was done on the domain of menstruation. Through the various researches it was found that in comparison to boys girls were more embarrassed by the pubertal changes and the major concern was related to height and weight. $20.08 \%$ girls reported having restriction in activity at home while $30.13 \%$ reported in having restriction at school due to menstruation. A large number of girls reported feelings of shame and guilt in the aspect of menstruation while a few of them considered it to be an abnormal phenomenon. Mostly adolescence in the age group of 12-14 all over India also had the average age for pubescence among boys and girls to be 12.6 years. The most amount of information directed towards the 
adolescent girls in the sphere of menstruation was mainly by the mother and very less information was passed on by the media and it was also seen that girls a majority of girls had poor knowledge about menstruation. A study by Gupta et al. also proved that a very small number of adolescent girls possess good knowledge. It was also found that teacher had a meager role to play in educating the adolescence about menstruation and the hence the urge of the present time is mainly a need to educate parents, teachers and adolescent girls. One of the most common areas of thought among adolescent girls in relation to menarche was guilt. Joshie et.al conducted a research on the reproductive health of adolescents through which it was found that the most common concern was about the scanty or heavy menses while height and weight were not given into primary focus but few researches portrayed concern on all the aspects whether it was height, weight as well as heavy menses. In the sphere of masturbation there were more number of boys in comparison with girls who got indulged in the practice of masturbation and the reported after effects which were mainly reported by the adolescence were body ache, guilt, pimples and change in the shape of penis. In the domain of masturbation there are not many studies in respect to girls keeping in mind about the cultural sensitivity. Sathe et al. conducted a research study in Pune and they did not ask girls about statements related to menstruation as it was considered to be culturally sensitive issue. On the other hand the research conducted by Shashikumar R. et al showed that adolescent girls seek more information and clarifications and one of the most common question asked during the research study was the meaning of masturbation. The heightened difference in reporting about masturbation may be due to girls not masturbating as boys do or it is due to embarrassment and ignorance felt. The frequency was also much less in girls as compared to boys. The reason as to why the adolescent boys and girls are ignorant and have poor knowledge about masturbation and just a few percentage having good knowledge about masturbation is mainly due to the presence of cultural sensitivity in the topic and there is a high risk on part of the adolescence to suffer from guilt, anxiety and concerns about the outcome of masturbation and it was also found through the various researches that those who comparatively possessed a good knowledge about masturbation and comparatively is aware of the pros and cons tend to have a positive attitude in life and towards life. It has been widely prevalent across nations that there is a misconception and a false notion related to masturbation not being normal or considered to be harmful. When a study was conducted at Iran, the results portrayed that among boys 53\% considered masturbation to be abnormal and on the other hand the research scholars Sathe and Sathe also said that there were a large number of adolescent boys who considered masturbation to be a cause for a disease. In contradictory when Lalet. al conducted a research study in Kerala they found that $51.2 \%$ boys and $15.3 \%$ girls disagreed to the very fact masturbation was harmful and through researches it has been portrayed that there were report in fear of change in the morphology of penis, aches, fatigues as they were few common adverse effects reported due to masturbation. The major task which lies on the hands of psychologists, sociologists are to mainly eradicate these leading misconceptions from the mind of the adolescents as it can lead to severe sexual impairment in adulthood disrupting areas like relationship, family etc. According to the research study by Shashikumar R. that $22.4 \%$ of the adolescents had experienced nocturnal emission. Nocturnal Emission is also termed as "wet dreams". The research also portrays that the percentage mainly comprises the majority to be boys who have had experienced wet dreams. But when Sathe conducted a similar research in Pune they found a higher rate in the percentage of the population who reported about nocturnal emission. While on the other hand when a research study was done on adolescents on the domain of Sexuality and Sexual Behavior by Sharmila SP, Chaturvedi there were only $18.33 \%$ boys who mainly have had experienced nocturnal emission. On the similar lines when a research was conducted on the adolescents in the sector of Perception and Practice with regard to Reproductive Health among Out of school adolescents it was found that $67 \%$ boys and $53 \%$ girls considered nocturnal emission to be normal.

Another significant aspect discussed through the researches was about sexual contact which was indicated in the areas of having touched private parts, kissing or sexual intercourse. In this domain a large number of boys compared to girls reported of having had sexual contact. A very high majority of boys with a very less number of girls reported in having experienced sexual intercourse which can also be linked to the risk factor and the thought of experimenting with life as a whole during adolescence. Through the researches reviewed it was found that the average age for boys having sexual contact and experiencing sexual intercourse was 13.72and 15.25 while on the other hand for girls it was 14.09 and 16.66 for engaging in sexual contact or being engaged in sexual intercourse. But still there was the reason for not having sexual contact was mainly highlighted on sexual contact and intercourse being unhealthy and hence to be avoided. In the sphere of sexual experience it is not surprising to note down the fact that adolescents of India are very much aware of the concept of premarital sex. Leena Abraham conducted a research study on the Risk Behavior and Misconception among Low Income college students of Mumbai and found that $12.6 \%$ of girls were aware about premarital sex and $49.3 \%$ of boys were aware about premarital sex. But there was a difference observed in the incidence of reporting of sexual intercourse among few researchers. Contradicting to the other researches the research conducted by Shashikumar et al. on Understanding Sexuality among Indian Urban adolescents portrayed reluctance on the part of the adolescent students to disclose or they must have had less opportunities to open up 
their view points.. The results for sexual experience varied from UK and USA as the age at coitarche was much higher than in UK where up to $20 \%$ of 13 years olds have had premarital sex according to a research study by Burrack (1999) on Teenage Sexual Behavior-Attitude towards and declared sexual activity while it was lower than in the USA where the average age for boys is 10 years and for girls it is 17 years. According to a survey conducted in Delhi it was found that the mean age of first sexual contact was 19.57 years for boys but that for girls it was 16.95 years. In the aspect of sexual partners the most preferred fantasized sexual partner was a classmate which in turn was followed by film stars irrespective of gender. A very small population among girls fantasized in having sex as compared to boys. For both boys and girls they preferred a friend to be their sexual intercourse partners and few preferred an unknown person or a relative to be their sexual partner. Through the research a very interesting result was brought into focus that when boys indulge themselves into sexual intercourse the most commonest partner was found to be a friend and it was reported by almost $78.37 \%$ while a very few percentage of $13.7 \%$ has considered other people to be their partners and it was also said that the others can comprise of commercial sex workers as well. According to a research study by KP Lindgren et al on WH. College students' perceptions about alcohol and consensual sexual behavior: Alcohol leads to sex (2009) and another research study by S. Assanangkornchai et al on Prevalence and patterns of alcohol consumption and health risk behaviors among high school students in Thailand (2009) it was found that there exists a significant relationship between alcohol and varied sexual activities. Where on one side women consume alcohol to portray their sexual willingness or restrain themselves from sexual advances directly while on the other hand it was found that men consume alcohol to facilitate sexual advances. Partying late nights can encourage the individual to consume more amount of alcohol and get in to more health risk behaviors. According to a research study by the World Health Organization (2005) it was found that alcohol and sexual activity does not only independently pose health risk behaviors but also trigger the incidence of suicide among teenagers and hence it is suggested that students or adolescents should also be educated in the sphere of alcohol and the various ill effects that it possess. JJ Plaud and his colleagues conducted A multivariate analysis of the sexual fantasy themes of college men in the year 1997 and they referred sexual fantasy to a private or covert experience in which the imagination of desirable sexual activity with a partner is sexually arousing to the individual and it has been proved by various other researches that fantasy level is positively correlated with greater range of sexual activity. The reason stated for indulging into sexual intercourse was mainly for curiosity and it was also reported as being forced into among the girls while on the other hand for boys it was mainly due to fun and due to the uncontrollable desire. But a very interesting research result came into focus that boys were also forced into getting indulged into sexual intercourse by their girlfriends. Hence there should be an enhancement in the awareness among the adolescents so that they think twice before engaging into risky behaviors and to have alternate ways for having fun and controlling their desire. Through the researches reviewed by the author it was found that on the aspect of communication problems with opposite gender boys tend to face more problems which is twice as much compared to girls than when girls had the communication with boys. On the other hand Sathe and Sathe conducted a similar research about Knowledge and Attitudes about Adolescent Sexuality in Pune and through their study it was portrayed that $72 \%$ boys had reported in having difficulty in communication with girls while $80 \%$ of girls reported in having difficulty in conversing. The most reported fear in the domain of communication was mainly the fear of rejection in the peer group. "Empirical evidence indicates that adolescents whose parents communicated openly with them about sexuality when they were young report feeling much comfortable discussing sexual topics with their parents and are more likely to make personal decisions about sexual behavior that reflect parental values and morals"'(Brock \& Jennings, 1993; Fisher, 1988). According to Sathe and Sathe (2005) boys reported more of lack of communication skills than girls while girls were mainly held back from communicating due to the fear of elder as the significant cause. Boys reported socioeconomic differences as also the cause. S.J Jeebonbhoy and S.Bhot conducted a research on Nonconsensual sexual experiences among young people: A review of the evidence from developing countries (2003) and found that there were high rates of sexual abuse among school going children. In the USA it was found that $15 \%$ of boys and $28 \%$ of girls were sexually abused. The very fear that knowledge of sexuality in the adolescents and preadolescents mind may involve them into premature sexual behavior and also there is a lack of comfort which prevails in the communication as discussed earlier. According to the research study on Understanding sexuality among Indian Urban school adolescents by Shashikumar et al. (2012)it was found that 48.18\% abused boys reported the penetrator to be a friend and for girls the most reported person was a stranger. Close relatives comprised of the most number of abuses in comparison to distant relatives. Boys feel threatened about their masculinity and there is a stigma involved which makes the boys suppressed in discussing trivial details like this and it has been found that the consequences faced by both boys and girls are of the same degree irrespective of the gender. For boys there can be a sense of suicidal ideation and in many cases a sense of femininity probes in and that those who are the victims of sexual abuse are in higher risk of having HIV infection. Researchers portrayed that boys had more knowledge regarding HIV in comparison to girls while on the other hand few researches also focused on the fact that half of both boys and girls were either unaware about 
HIV and Sexually Transmitted Diseases and was ignorant and sometimes they just ignored it. It has been highly suggested that there should be gender based sex education regarding Sexually Transmitted Diseases, safe sex and contraceptives in schools in India. Another major research finding was that more number of boys in comparison to girls was aware to the fact that single sexual intercourse can lead to pregnancy. But in a study from Lagos it was found that $80 \%$ of the students were not aware of the fact. A research study by Eaton et al. 2006 portrayed that nationwide $14 \%$ of students had sexual intercourse during their lifetime with four or more sexual partners. Among the currently sexually active students $37 \%$ reported that they or their partner did not use a condom during their last intercourse. It has been proved through research study that Miller et al. in 1998 that prevention messages delivered to adolescents before onset of sexual risk behavior are most effective. Parents and other family members play the most critical role in shaping adolescent sexual behavior through the various parenting practices and through the different sexuality communications. And modeling of risk reduction and strategies. Researches have proved that greater parental monitoring and less parental permissiveness are consistently related to later sexual initiation, less frequent sexual intercourse, less risky sexual behavior, fewer sexual partners, less pregnancy and increased condom use among teens. When there is a greater communication about sex between parents adolescent it leads to less risky sexual behavior. "Parents may neglect the responsibility they feel for the sexuality education of their children because they are uncomfortable with their own sexuality or are uncertain about what the children need at different ages"( Croft \&Asmussen, 1992). Sarah C. Wyckoff et al conducted a research study on the Patterns of Sexuality Communication between Preadolescents and their Mothers and Fathers (2007) focused on the communication about sexual topics between preadolescents and their mothers and fathers. The research mainly focuses on the patterns of communication between African- American preadolescents (9-12) and their parents using reports from preadolescents, mothers and fathers talking with their preadolescent and the likelihood of communicating the topic of sexuality and the discrepancy in the communication as report by the preadolescents and their parents. It has been portrayed through various other researchers that mothers communicate more about matters or topics related to sexuality than fathers do with their children. "Furthermore, the accuracy or inaccuracy of the information passed on to children, punishing or no punishing responses to sexual questions or behaviors, nonverbal cues, and questions answered or ignored are all influenced by a parent's comfort with sex-related topics"(Davis et al. 1986). According to DiIorio et al. mothers play the primary role of sex educators at home. But another contradiction which was found that mothers are more comfortable in conversing with girls while fathers are more likely to converse with their sons in matters relating to sexuality which can be justified with the very fact that parents' knowledge or perceived knowledge about the varied topics about sexuality may influence their conversation with their children. But researchers have also proved that it is mothers rather than fathers who are comfortable in discussing about topics related to sexuality with both sons and daughters. Studies shown that when parents employ open and interactive communication styles, their children demonstrate greater knowledge on sexuality. The communication between preadolescents and their parents were assessed through the measure of 10 items which comprised of 8 sexuality topics and 2 items related to alcohol and drug use, both are which risk factors for sexual behavior and other specific sexuality topics comprised of communication about dating, puberty, menstruation, information about sex, abstinence, reproduction and condoms and another topic was about HIV/AIDS. The response set was divided into categories which were Never, Once or Twice and Lots of times and due to the limitation of the categories the responses were categorized under Never or Ever (once/twice). After factor analysis was conducted three major factors emerged which are- risk factors (alcohol drugs), sexuality education (puberty, menstruation, reproduction, dating) and sexual risk prevention (condoms HIV). The parents and preadolescents were assessed on the ten distinguished topics and whether they had communication on the above mentioned areas. Through the research study it was found that a majority of parents and their preadolescents report communication about risk factors, sexuality education and sexual risk prevention topics and it was also found that there were least or negligible discussion about condoms. Sexuality education topics like puberty, reproduction and what is sex all about were discussed by majority of the participants but these topics were least discussed between fathers and daughters. The discussion on menstruation was discussed by majority but mostly between mothers and daughters. Topics like Abstinence was not discussed by any of the participants neither son nor daughter or fathers. The domain of sexual prevention in the context of condoms was not discussed by a majority of the population. Excitingly it was found that mothers and fathers reported discussing about HIV with their children but a minority of preadolescents supported this view of having discussion about HIV/AIDS with their parents.

In the domain where it was asked whether communications about sexuality between parent and child dependent on gender it was found that for sons there was a consistent scenario whether it was son or parent there was not much significant differences in any of the topic discussed and it was found that both parents have equally discussed topics with their sons. On contrary it was found that there was a higher significant difference was observed for 8 out of 10 topics where there were a higher percentage of mothers than fathers reporting a conversation with their daughters as was reported by either parent or daughter. It was found that a higher 
percentage of mothers than fathers have discussed risk factors and sexuality topics with their daughters than with their sons, whereas it was found that mothers and fathers are equally likely to discuss all topics with their sons. Finally on the domain whether children and parents differ in the likelihood of reporting that sexuality communication have occurred there was no significant differences found denoting to the fact that similar percentages of parents and preadolescents, regardless of gender and reporting whether a communication had occurred. Through the research study and the report by both parent and child, a majority of parents participating said that they communicate with their preadolescents. According to the Kaiser Family Foundation, 1999 it was said that youth identify parents as their preferred source of getting education on the facts of sexuality education. And the fact that topic like what sex is and abstinence and the use of condoms and topics related to HIV/AIDS were least discussed but it has been said that in spite of being hesitant to discuss about topics related to sexual risk prevention and what sex is all about are important components of sexuality education and should not be avoided from discussion. It has also been studied that parents who have more knowledge in the various aspects of sexuality feel more free and comfortable to discuss about sexuality and it has been highly suggested that there should be strengthening of family communication about topics related to sexuality and it should be enhanced through educational programmes. There is a difference found between communication between parents and preadolescents and their gender. Mothers are more engaged in discussing about various aspects of sexuality with their daughter and hence it can also be said that mother act as primary parental sexual educator of their preadolescent daughter but in contradiction both parents are equally involved in discussing about various sexuality topics with their sons. It has also been found that fathers may not feel comfortable in discussing about sexuality related topics with their daughters than they do it with their son may be due to lack of knowledge.

According to Tolman in the year 2002 adolescent girls and boys have different information, values, expectations and different perspectives in the domains of sexuality and sex education and the main agents of gendered sexual socialization at adolescence has been indicated mainly to school based sex education, peers ad media. According to Shelly Saha adolescence is a period of life which is mainly characterized by relatively good health where in the vulnerability to infectious childhood diseases is mainly reduced and the illness of adulthood and childhood are kept further off. It has been proved through the vast pool of literature that has been reviewed that early sexual initiation can lead to tragic social, economic and health consequences. In the present scenario the main reasons for the changing patterns of sexual behavior among people are mainly due to the global availability to mass media, migration, change in family structures, loosening of traditional constraints etc. Young people in the urban areas marry later and may indulge into varied sexual behaviors among which one is getting engaged into premarital sex. And hence risking their life to unwanted pregnancy and Sexually Transmitted Disease. As sexuality is one of the most conservative topics to be discussed in India there are not many studies which have tried to elicit information on the sexual behavior. But according to a research study by Jejeebhoy (1996) adolescents not only from urban but as well as rural are indulging themselves in varied sexual activities. The trend which has been found in the present day society at large in India there was found to be an increase in the Sexually Transmitted Diseases prevalence among young people with a rapid increase in HIV infections among 15-24 years. There was shown to be an inadequate knowledge about reproductive health and needs and there is a higher rate of early marriage and early pregnancy. Through researches it was also portrayed that there was a high fertility rate among adolescents. Now when the main question comes about why there is a need to provide sex education, the most prominent reason that can be seen in the forefront is that adolescents do not have adequate information regarding their own sexuality, physical well-being and their health and the major information that they received about sexuality in the present days are mainly from the peers and the media at large and the knowledge they have received are mostly incomplete in its nature or they are way confused with the excessive amount of information from varied sources. According to researches the increase in unwanted pregnancy, illegal abortion, mortality and morbidity among young girls is mainly due to the low rate of educational attainments, limited ex education activities and the suppressed attitude towards sex which in turn leads to the heightened ignorance about the varied topics in relation to sexuality education. It has also been portrayed through researches that the knowledge differs from gender to gender and also the fact that uneducated rural girls have least information about varied topics related to sexuality and there is a gender bias present and a double standard favoring boys prevails. There is a conservative thinking that in our societies "good" girls are not supposed to know about sex and hence adolescent girls are forbidden from seeking information. According to a study conducted by Family Planning Association of India (1991) among teenagers portrayed that one-fourth of the respondents expressed their acceptance of premarital sexual contact, indicating to the varied trends that are rising in the Indian society at large. Maitra et al. conducted a survey on 959 adolescents on the issues of sexuality education portrayed that regardless of age and education all the subjects have expressed the need for the introduction of sexuality education in the curriculum. On the other hand in the year 1989 a study was conducted in rural Maharashtra by SEARCH which focused on the factors that nearly half of the unmarried girls had already experienced sexual intercourse signifying the need to provide sexual health education among the rural people in the villages. It has been portrayed through the carious study that due to the low income and high 
illiteracy rates and ignorance about sex and reproductive physiology leads to the vulnerability of suffering from varied Sexually Transmitted Diseases and RTIs.

"Early Intervention by targeting adolescent girls with family life and sex education as well as programme to improve their self-confidence and social status may be an effective way to safe guard their future health status (Blende : 1994)

"Transmission of values and attitudes about sexuality from parents to children is inevitable; values and attitudes are transmitted whether parents choose to actively participate in the sexuality education of their children or are neglectful in the matter (Allen \& Baber, 1992; Calderone, 1989; Goldman \& Goldman, 1982; Klein \& Gordon, 1992)

Roberts et al. conducted a study in the year 1978 on parents of 3 to 11 year olds and came to a conclusion that parents strongly feel and believe that one conversation regarding topics related to sexuality is more than sufficient in the development of the child.

"The teachers, administrators and students comment that isolation, abstinence from sex and avoidance of all forms of romantic love and sexuality are the key strategies to protecting the girls' education."

Through a study by Hulton et al, in the year 2000 he portrayed that youth are aware about the problems that early sexual encounters possess but face difficulties acting on that knowledge due to gender roles as it was also shown that boys' sexual activity is condoned as initiation into manhood as is the lack of responsibility for their behavior and girls feel powerless in this regard. Due to the complicated sexual and gender expectations it poses threats for girls. There is a strong belief which prevails that boys and men will, are allowed and even encouraged to have intercourse and also been pointed out that girls need to be protected, isolated and restricted in their movements in order to avoid possible sexual encounters with boys or men who generally tend to "move around freely".

"Culturally, the girls are expected to be passive and subservient to men and the strategies of isolating them and teaching them about abstinence and avoidance of romantic love and sexual

Activity perpetuates this passive femininity. In addition, rather than asking questioning or condemning aspects of masculinity ; it is the girls who tend to be blame or punished or mistreated if a pregnancy occurs, especially since there is some unwarranted expectation that they should know how to keep themselves from getting pregnant."

There has always been culturally a hegemonic masculine sexuality which has been encouraged and at times socially constructed as uncontrollable and hence creating a dangerous situation for girls who are tend to be trained to be passive in the face of masculine power and uninformed about sexuality at large and there is a presence of conflict in the teachers minds about their own feelings toward contraception and lacked information and experience in discussing topics in relation to sexuality also due to the fear of judgment of community members about the positive attitude towards engaging into explicit discussion of sexuality.

A research study based on the Sexuality Education of Children and Adolescents with Developmental Disabilities by the American Academy of Pediatrics proved that there exists an inhibition about discussing topics related to sexuality education not only in the mainstream society but also for children suffering from disabilities. Sexuality education pose a challenge to many parents of children with developmental disabilities as they deny the child's sexuality, have a constant fear of sexual exploitation or pregnancy and have a difficulty in terms of deciding about what are the things that should be communicated related to sexuality and which are the factors which should not be appropriate. It has also been said that pediatricians should incorporate guidance on sexuality education, socially appropriate behavior and sexual abuse prevention into the clinical supervision of children suffering from various disabilities and also are

asked to get more involved with the children and their parents by guiding the parents in the right direction about talking with various matters related to sexuality so that they can impart the attitudes and teach the behaviors and information that are most likely to help the children with developmental difficulties to achieve a sense of personal satisfaction and behave in ways that are socially appropriate, and also protect them from exploitation.

The various sex education programmes which are held shows that it helps to the maximum level in helping the parents in involving themselves with their adolescents in relation to sexuality which in turn imparts knowledge in the adolescents' mind and brain which are more concrete in nature as parents play the most important role as sex educators and media and peer plays a secondary role with mostly vague information carried. Through the research studies on sex education programme it has portrayed that parents felt that the meetings through the sex education programme increased their own personal comfort and confidence regarding the attitudes they possess in regards to sexuality and there is an increase in satisfying communication with their adolescents. Hence researchers showed through their various researches that there should be sex education programmes conducted so that it helps in the reduction of STDs, pregnancy rates, infertility etc. 


\section{Summary and Conclusion}

The World Health Organization (2004) defines sexuality as a central aspect of being human throughout life and encompasses sex, gender identities and roles, sexual orientation, eroticism, pleasure, intimacy and reproduction. Sexuality is experienced and expressed in thoughts, fantasies, desires, beliefs, attitudes, values, behavior, practices, roles and relationships. While sexuality can include all of these dimensions, not all of them are always experienced or expressed. Sexuality is influenced by the interaction of biological, psychological, social, economic, political, cultural, ethical, legal, historical, religious and spiritual factors. The way information is put across to the children varies as there are gender differences prevalent.

Adolescence literally means to grow in maturity and refers to the period when an individual has attained reproductive maturity but has still to grow into physical, mental, emotional and social maturity and that is necessary to function in the adult world. Adolescence, the word conjures up images of tumult and change; of rebellion and self-centeredness. The origin of the word Adolescence is from the Latin verb 'adolescere' which means "to grow up". It can be conceptualized as the transitional stage of development between childhood and adulthood marked by several psychological changes. Adolescent is a very discretionary stage in one's life growth. Adolescence generally lasts from 11 or 12 years to late teens or early 20's.Adolescence is a social construction. Emotional maturity may depend on such achievements as discovering one's identity, becoming independent of parents, developing a system of values, forming relationships and so on. Adolescence is a time of opportunities and risks and hence age becomes a powerful bonding agent in adolescence.

Parents play the most important role in educating their children about sexuality but sometimes parents are afraid to share information. The parents face problems regarding the very fact that they are uncomfortable talking about reproductive body parts and functions. For many parents, the topic of sex never came up when they were growing up. They wonder if talking about sexuality and reproduction will encourage their children to experiment. The fact is young people, whose parents discuss all aspects of sexuality with them, tend to delay becoming sexually active, compared to those parents who do not discuss this topic. They are not sure what their children need to know and at what age they need to know it. Sexuality does not relate only with sexual intercourse and sexual activity, it has a major role to play with the fact of being female or male, and how females and males are alike and different in the way they look and act; how we view our bodies and our relationships with each other; how we grow and change over the years; who we are as women and men (girls and boys); and how we reproduce. Past researches has proved that mothers play the role of primary sex educators for their children providing them with necessary information than fathers do. The major problem area where parents required help was to address their own conflicting feelings about sexuality, exploring their own attitudes and values, obtaining accurate information, developing their communication skills and understanding their roles as sexuality educators (Alter \& Wilson, 1982).

Parents and other family members play critical roles in shaping adolescent sexual behavior through their parenting practices, sexuality communications and modeling of risk reduction strategies. Greater parental monitoring and less of parental permissiveness are consistently related to later sexual initiation, less frequent sexual intercourse, less risky sexual behavior, fewer sexual patterns, less pregnancy and increased condom use among teens ( $\mathrm{Li}$ et.al.2000; Miller et al.1999; Romer et.al.1994.).One of the articles focuses on the fact that how gender roles hinder sexuality education for girls in a Ugandan school, leaving the girls vulnerable to HIV and pregnancy. Another article focused on women who were 30 years old and their childhood experiences in gathering or obtaining the information about sexuality.

The results obtained from the different researches that were reviewed portrayed that parents are unsure about how much sex-related information is appropriate and when it is the right time to provide it to children and parents worry that they could give their child too much information too soon. It is also portrayed that sometimes parents are fearful about other parents. There is a dialectical tension present which should be addressed to bring in a homeostasis. Parents believe that they have an urge to do better than their parents as and when they have shared the earliest memories of sexuality education and they felt that their mothers could have been open and more comfortable with sensitive issues like this to gain a better understanding and that inadequate information was provided which mostly involved warnings and rules to be obeyed. It was clearly portrayed through the different research studies that Mothers play the role of primary sex educator and it is evident from the facts obtained that mothers talk more with daughters than sons about domains like relationships, reproductive bodies, morality but no significance difference in the aspect of discussion of topics like sexual abuse. But in few research studies it has been portrayed that sons are more comfortable to discuss with fathers and their mothers. The ease of discussing the subject matter with the same sex parents is comfortable. Though parents try to portray the fact that there is no gender difference involved in imparting the knowledge but through the research studies it is proved that there is a gender difference involved in discussion about aspects of sexuality. Moral issues related with gender come into highlight. It is found through the studies that youth identify parents as their preferred source for sexuality education and parents has willingness to be sexuality educators for their children but it would be better communicated if focus groups were present and parent programme was arranged where 
there will be no stigma attached and no taboo regarding the discussion of topics like sexuality. Through the review of articles it was also found through previous researches that both middle class and working class parents indicated a high degree of comfort discussing sexuality topics with their young children. While in the working class parents in few studies it was shown that mothers mainly provide the information whereas in middle class parents both parents were involved in giving the information to their children.

The limitations for the articles reviewed were mainly that the articles focused on few groups of the society and hence there was a cultural difference which could be observed. The questions that were asked in the different articles mostly highlighted towards the girls and hence the results of the boys may have differed if there was equal justification of questions between two groups. The articles mainly had mothers as their primary sex educator and not much information was gathered from the co-parent. One major limitation was that there was no representative study conducted and only 16articles were reviewed and analyzed. There were a very less number of Indian studies conducted in regards to sexuality as it is a taboo to discuss about sexuality.

There is a heightened scope for further research with first hand data to be collected to gain knowledge about the mentioned topic with a more representative sample from the Indian scenario and the study can be improvised by including a wider age group of samples, belonging to different cultures and nationalities.

\section{Acknowledgement}

Never feel alone, there would be at least someone who would be holding your hands through the darkness

To the Light...

One cannot create anything without the help of a thousand helping hands and the rise of creativity is through the careless words, thoughtful comments or even encouraging gestures.

On this regard I would like to thank God for giving me all the grace, the motivation, the strength and confidence within myself to successfully complete the dissertation.

I would take this opportunity to thank my parents, grandparents, cousins, relatives-near and far for believing in me and my abilities.

I am thankful to Christ University for having given me the opportunity to do this dissertation. I will always be grateful to Dr. (Fr.) Thomas C. Mathew, Vice Chancellor of Christ University, Dr. AnkurMadan, our class teacher and Dr. Tony Sam George, Head the Department, for being a constant support. I wish to place on records my profound thanks to Mr.Jini K. Gopinath, Assistant Professor and distinguished guide for his support, advice and continuous help. I don't find myself anywhere without his continuous support, encouragement and expert guidance.

I would always be grateful to the most wonderful bunch of friends ReshmaElza Abraham, Branca Maria Docormo Pereira, Nitya Nair, Roy P., Shruti S., Paavana K., and Rhea Choudhury who are more of my family than my friends and thanks to them for bearing my poor jokes at any point of time of the day and helping me throughout with the unconditional motivation, love and care and a very special thanks to Neville K., ShagunGuha, all my seniors from Msc Clinical, MscCounselling and Msc HRDM, my hostel friends, warden for helping me at all the points where I was on the verge of breaking down and helping me stand straight with my head held high.

I wouldn't be here without the unconditional support, love and blessings of Mrs.Somdutta Banerjee, Dr. Elizabeth Jasmine, Mrs. BhaswatiChakroborty, Mr.Stefen Samuel, Mrs.DebleenaBhattacharjee, and Father Viju who gave me the strength to overcome all hurdles and stay strong always with a smile.

Lastly I would extend my heartfelt gratitude to the cyber cafes in S.G.Palya, Jonas Hall Hostel for giving me the most comfortable surroundings, the Internet and Christ University Knowledge Centre for providing me with all possible information and help whenever required.

When you feel you don't have any hope, just close your eyes and smile, you will realize there are lots of reasons to smile for than to cry about.

[1]. Amir, I. (2009, 04 26). Sex education: Why India should go all the way. Retrieved from http://articles.timesofindia.indiatimes.com/2009-04-26/view-from-venus/28022348_1_child-marriage-indian-women-educationclasses

[2]. Brock J., L., \&Jeggings H., G. (1993). Sexuality education: What daughters in their 30s wish their mothers had told them. National Council of Family Relations, 42(1), Retrieved from http://www.jstor.org.stable/584923

[3]. Burns, K. (2002). Sexuality education in a girls' school in eastern Uganda. Agenda Feminist Media, (53), 81-88. Retrieved from http://www.jstor.org/stable/4548060

[4]. Dasgupta, A. (2012, 3 26).Importance of sex education among the youth. Retrieved from http://www.onlymyhealth.com/importance-sex-education-among-youth-1301382451

[5]. Douglas, K., Lynn, P., \& Jean G., B. (n.d.).A joint parent-child sex education program.

[6]. Geasler J., M., Dannison L., L., \&Edlund J., C. (1995). Sexuality education of young children: parental concerns. Family Relation, 44(2), Retrieved from http://www.jstor.org/stable/584807 
[7]. Karin A., M., \& Katherine, L. (2010).Gender differences in the ABC's of the birds and the bees:what mothers teach young children about sexuality and reproduction.

[8]. Mayo, C. (n.d.). Sexual health. Retrieved from http://www.mayoclinic.com/health/sex-education/CC00032

[9]. Ramadugu, S., Ryali, V., Srivastava, K., \&Prakash, J. (2012).Understanding sexuality among Indian urban school adolescents.Department of Psychiatry Armed Forces Medical College, Pune, Maharashtra, India.

[10]. Reiss, M. (2005, 09 07).A brief history of sex education. Retrieved from http://www.open.edu/openlearn/body-mind/health/healthstudies/brief-history-sex-education

[11]. Saha, S. (2012).Adolescents and their need for sex education.

[12]. Sex education.(n.d.). Retrieved from http://www.sciencedaily.com/articles/s/sex_education.htm

[13]. Sexuality education.(n.d.). Retrieved from http://www.moe.gov.sg/education/programmes/social-emotional-learning/sexualityeducation/

[14]. Sex education in India.(2012, 09 25). Retrieved from http://education.intoday.in/story/sex-education-india-school-rape-teenagepregnancy/1/222128.html

[15]. Sex education in Indian schools: The need of the hour. (2012, 02 25). Retrieved from http://www.youthkiawaaz.com/2012/02/sexeducation-in-indian-schools-the-need-of-the-hour/

[16]. Sex education for teens.(n.d.). Retrieved from http://www.medindia.net/patients/patientinfo/sexeducation.htmKesterton, D. (2012, 05 30). Sex education: what role should parents play?. Retrieved from http://www.guardian.co.uk/society/2012/may/30/sexeducation-parents-role

[17]. Sarah C. , W., Kim S., M., Rex, F., J.J., B., Amy, F., Nicholas , L., \& Lisa , A. (2007). Patterns of sexuality communication between preadolescents and their mothers and fathers.

[18]. Scales, P. (1986). The changing context of sexuality education: paradigms and challenges for alternative futures. National Council of Family Relations, 35(2), 265-274.

[19]. Timothy R., J., James H., P., \& Shawn, F. (2000).Rural parents' communication with their teen-agers about sexual issues. The Journal of School Health,

[20]. (n.d.). Retrieved from http://www.betterhealth.vic.gov.au/bhcv2/bhcarticles.nsf/pages/Sex education talking to teenagers

[21]. (1996). Sexuality education of children and adolescents with developmental disabilities. Pediatrics, 97

[22]. (1971). Evaluation of a sex education program for children and their parents: attitude and interactional changes. The Family Coordinator, 